\title{
Análise de inscrições em livros didáticos de Química
}

\section{Analyzing inscriptions in Chemistry textbooks}

\author{
Mikeas S. de Lima, Henrique M. Larine, Douglas G. L. dos Santos e Salete L. Queiroz
}

RESUMO: Apesar da importância e da disseminação das inscrições (representações visuais) no ensino de Ciências, é comum observar alunos com dificuldades na sua leitura, advindas principalmente da forma como são apresentadas no livro didático. Este trabalho tem como objetivo investigar as características das inscrições de dois livros didáticos empregados no ensino superior de Química no Brasil. Nessa perspectiva, foi realizado o estudo semântico e funcional das inscrições, considerando os seus elementos externos, em especial o corpo do texto, a legenda e a indexação, e como o contexto fornecido por esses elementos auxilia na interpretação da inscrição. Foi possível observar inscrições com boa contiguidade física e alta indexação. A maioria das inscrições está acompanhadas de legendas, porém pouco informativas, o que pode representar obstáculos que os alunos enfrentarão durante a utilização dos livros analisados. A identificação das potencialidades e fragilidades das inscrições em textos utilizados na sala de aula pode contribuir para que sejam encontrados meios para suprimir as suas deficiências e fomentar as potencialidades.

Palavras-chave: inscrições, livro didático, Química.

\begin{abstract}
Despite the importance and widespread use of inscriptions (visual representations) in Science Education, it is common to notice students who experience difficulties in reading inscriptions, mainly due to the way they are presented in the textbook. This study investigates the characteristics of inscriptions of two textbooks for higher education in Chemistry in Brazil. Considering this, the semantic and functional study of the inscriptions was carried out, considering their external elements, especially the body of the text, the caption, and indexing, and how the context provided by these elements helps to interpret the inscription. Inscriptions containing good physical contiguity and high indexation were observed. Most inscriptions are accompanied by captions, but they provide little information, which can represent obstacles that students will face when using the analyzed books. Identifying the potentialities and weaknesses of inscriptions in texts used in the classroom can contribute to finding means to suppress their deficiencies and foster their potentialities.
\end{abstract}

Keywords: inscriptions, textbooks, Chemistry.

\footnotetext{
Mikeas Silva de Lima (qmikeas @ usp.br), licenciado em Química pela Universidade Federal da Paraíba, é mestre em Química pelo Instituto de Química de São Carlos (IQSC) da Universidade de São Paulo (USP) e doutorando do Programa de Pós-Graduação Interunidades em Ensino de Ciências da mesma Universidade. São Carlos, SP - BR. Henrique Meisegeier Larine (hmlarine@ usp.br) graduando do Curso de Bacharelado em Química do IQSC. São Carlos, SP - BR. Douglas Gomes Lima dos Santos (douglasg@usp.br) graduando do Curso de Licenciatura em Ciências Exatas da USP. São Carlos, SP - BR. Salete Linhares Queiroz (salete@iqsc.usp.br) é doutora em Química pela Universidade Estadual Paulista e professora do IQSC/USP, onde coordena o Grupo de Pesquisa em Ensino de Química do IQSC (GPEQSC). São Carlos, SP - BR.
}

Recebido em 25/03/2021, aceito em 17/06/2021

A seção "Cadernos de Pesquisa" é um espaço dedicado exclusivamente para artigos inéditos (empíricos, de revisão ou teóricos) que apresentem profundidade teórico-metodológica, gerem conhecimentos novos para a área e contribuições para o avanço da pesquisa em Ensino de Química. 
As representações visuais possuem um papel importante na Ciência, assim como no seu ensino, que vai muito além de ilustrar os fenômenos estudados, sendo responsáveis também por registrar, guardar, organizar, compartilhar dados e informações, indicar tendências, evidenciar e servir de matéria-prima para conclusões, justificativas e argumentos, garantindo, dessa forma, confiabilidade ao conhecimento científico (Alves, 2011; Lima e Queiroz, 2020; Lima e Queiroz, 2021). Além disso, é frequente a presença do modo de comunicação gráfico-visual na sala de aula, nos livros didáticos de Ciências e em diversos outros contextos, de modo que um desenvolvimento adequado das habilidades e dos conhecimentos acerca do seu uso ganha destaque nos documentos curriculares brasileiros oficiais (Brasil, 2001; Brasil, 2019).

Latour e Woolgar (1997) utilizam o termo inscrições para nomear fotografias, desenhos esquemáticos, mapas, diagramas, fluxogramas, gráficos, tabelas, equações, entre outras representações visuais materiais que são intrinsecamente elaboradas durante a produção de conhecimento científico para retratar e estabelecer relações icônicas com seus objetos e fenômenos de estudo. Apesar da importância e da disseminação das inscrições no ensino de Ciências, é comum observar alunos do ensino básico e superior com dificuldades na sua utilização e leitura. Segundo Roth (2002), tais dificuldades advêm, principalmente, da forma como estas são apresentadas no livro didático, que se configura como o principal recurso no qual os alunos encontram e mantêm contato com inscrições. Portanto, é coerente e iminente a necessidade de estudos acerca do papel e do impacto das representações visuais no processo de ensino-aprendizagem de Ciências.

Ainda com relação ao livro didático, é central o seu papel na educação. De um lado, os professores se baseiam no texto para elaborar aulas, escolher o conteúdo e a abordagem de ensino. Os alunos, por sua vez, o consideram como um aliado em suas aprendizagens, principalmente quando o professor também o valoriza na sala de aula (Sillos e Santos, 2013).

Com base no exposto, este trabalho tem como objetivo investigar as características das inscrições existentes em livros didáticos usualmente empregados por graduandos em Química no Brasil, buscando a compreensão sobre elementos constituintes das inscrições que contribuem ou obstaculizam o desenvolvimento de habilidades necessárias para lidar com as mesmas (Brasil, 2019).

\section{Inscrições em textos científicos}

Desde a década passada, diversos autores vêm relatando o crescimento da utilização de inscrições em livros didáticos de Ciências, o que impulsiona as pesquisas acerca da presença de inscrições em textos científicos. De fato, Vojír e Rusek (2019), em sua revisão literária, demonstram que o estudo de representações não-textuais é um dos mais recorrentes nas pesquisas sobre os referidos livros, em especial na área da Química.
Tendo em vista a compreensão sobre o estágio do desenvolvimento dos trabalhos nacionais que tratam da presença de inscrições em livros didáticos de Química, foram identificados artigos sobre o assunto, sendo realizada uma busca levando em consideração o sistema de avaliação do Programa Qualis da Coordenação de Aperfeiçoamento de Pessoal de Nível Superior (CAPES), relacionado à área de Ensino, no triênio 2013-2016. Assim, foram selecionados periódicos nacionais, cujos títulos estão associados ao Ensino de Ciências classificados nos estratos A1 e A2. Embora não faça parte desses estratos, a revista Química Nova na Escola também foi investigada, devido a sua representatividade junto à comunidade de educadores químicos. O período de busca, 2008 a 2020, foi considerado suficientemente abrangente para permitir o acesso a um número significativo de trabalhos. Foram selecionados inicialmente todos os artigos que apresentavam o termo livro didático em seu título, resumo ou palavras-chave. A partir do resultado dessa busca, foram selecionados somente os trabalhos que tratavam da análise de inscrições em livros didáticos. Nesse contexto, foi identificado um total de 17 artigos que abordam a presença de inscrições em livros didáticos de Química. O Quadro 1 ilustra a distribuição dos periódicos e a quantidade de artigos localizada em cada um deles.

Quadro 1: Quantidade de artigos que abordam a presença de inscrições em livros didáticos de Química.

\begin{tabular}{|l|c|}
\hline Periódico & Número de artigos \\
\hline Ensaio & 1 \\
Ciência \& Educação & 2 \\
Acta Scientiae & 2 \\
Amazônia & 0 \\
Areté & 1 \\
Investigações em Ensino de Ciências & 1 \\
Revista Brasileira de Ensino de Ciência e & 1 \\
Tecnologia & 1 \\
Revista Brasileira de Pesquisa em & \\
Educação em Ciências & 1 \\
Revista de Educação, Ciências e & 7 \\
Matemática & \\
Química Nova na Escola & \\
\hline
\end{tabular}

A leitura dos artigos presentes no Quadro 1 sugere que a pesquisa acerca de representações visuais em livros didáticos de Química ocorre em três perspectivas:

- análise das possíveis interpretações e produção de sentidos que podem ser atribuídas a determinadas inscrições presentes em livros didáticos (Bianco e Meloni, 2019; Rozentalski e Porto, 2018; Lemes et al., 2010; Rozentalski e Porto, 2015; Moreira e Batista 2018; Silva e Almeida, 2019; Meloni e Lopes, 2020);

- análise descritiva de inscrições, ou seja, análise da quantidade, tipos, elementos associados (legendas, rótulos etc.) e 
funções didáticas de inscrições presentes em livros didáticos (Miranda et al., 2015; Pazinato et al., 2015; Silva et al., 2013; Goes et al., 2018);

- análise de inscrições dentro de um contexto mais amplo, que abarca diversos outros aspectos do livro didático, como por exemplo, discurso verbal, atividades experimentais etc. (Toledo e Ferreira, 2017; Bedin, 2019; Cassiano e Echeverría, 2014; Chaves et al., 2014; Canzian e Maximiano, 2010; Matos et al., 2009).

Nas duas primeiras perspectivas, as inscrições são destacadas na análise, enquanto na terceira não possuem tal status, estão apenas inseridas em certo contexto. $\mathrm{O}$ fato é que as perspectivas identificadas põem em foco a centralidade e a estreita relação das inscrições com o desenvolvimento do conhecimento científico por meio do uso do livro didático. Com base no objetivo proposto anteriormente, nos juntamos ao rol de pesquisadores que realizam a análise descritiva das inscrições presentes em livros didáticos de Química.

Segundo Roth et al. (2005), os diversos tipos de inscrições estão distribuídos ao longo de um continuum, ou cascata de inscrições, como a da Figura 1.

Numa das extremidades do continuum das inscrições está o mundo dos fenômenos e objetos (MFO), e na outra, o mundo dos conceitos e teorias (MCT), de modo que a proximidade da inscrição com um desses mundos diferencia os esforços requeridos para a sua leitura. Quanto mais próxima da extremidade do MFO a inscrição estiver, como fotografias, mapas e desenhos icônicos, menor é o nível de abstração e maior a quantidade de informação contextualizada e detalhes que ela pode apresentar, como também maior a semelhança da inscrição com o que ela representa. Os esforços de leitura requeridos estão vinculados ao estabelecimento de relações de identificação das semelhanças icônicas entre a inscrição, as suas estruturas visuais e os fenômenos representados.

As inscrições próximas do MCT, como gráficos, tabelas e expressões algébricas, não possuem, ou possuem pouca semelhança com os fenômenos que elas representam, ou seja, o nível de abstração e informações contidas na inscrição aumenta. Assim, uma leitura mais sofisticada é necessária (Roth et al., 2005). Por serem inscrições mais abstratas, a falta de elementos, como por exemplo rótulos, linhas de guia, entre outros, pode fazer com que a sua interpretação não seja realizada de modo satisfatório.

Além da sua posição no continuum, com base em Roth et al. (1999), entende-se que aprender a utilizar inscrições guarda relações com a aquisição de conhecimentos associados às práticas científicas e matemáticas que levam a sua concepção. A fonte primária para obtenção de tais conhecimentos é o livro didático (Bowen e Roth, 2002), e a forma como as inscrições são aí veiculadas desempenha um papel importante na apropriação das práticas de inscrições no decorrer da escolaridade. A partir disso, torna-se clara a associação da origem das dificuldades em leitura de inscrições, enfrentada por estudantes de diferentes escolaridades, com a maneira como estas são apresentadas nos livros didáticos (Silva et al., 2011), de modo que pesquisas relatam problemas de ordem estrutural, que se vinculam com os elementos internos das inscrições, e de ordem funcional, que se relacionam com elementos externos às mesmas.

O presente trabalho ocupa-se com o estudo semântico e funcional das inscrições, ou seja, com os seus elementos externos, em especial o corpo do texto, a legenda e a indexação, e como o contexto fornecido por esses elementos auxilia na interpretação da inscrição. Ressalta-se que, segundo Roth et al. (1999), corpo do texto e legendas são construídas por autores de textos científicos visando o fornecimento de restrições particulares à leitura de inscrições, apontando ao leitor as características percebidas pelos próprios autores ao utilizarem a inscrição para a demonstração de um conceito, ou seja, eles são projetados para barrar leituras diferentes daquelas dos autores.

\section{Corpo do texto}

O corpo do texto cria a estrutura na qual as inscrições e suas legendas são incorporadas, fornecendo descrições e instruções adicionais acerca de como inscrições específicas podem e devem ser lidas (Roth et al., 1999). Ou seja, o corpo do texto se configura como um dos locais no qual os autores podem incluir informações sobre as inscrições a fim de reduzir a sua flexibilidade interpretativa, pelo fornecimento de uma leitura, ou de instruções para a leitura de uma inscrição. Entende-se como corpo do texto o conjunto de elementos verbais escritos, diferente das legendas e títulos, que procuram explicar um conceito.

Algumas pesquisas indicam como o corpo do texto contribui para o entendimento das inscrições veiculadas em textos científicos. A título de exemplo, cita-se o trabalho de Bowen e Roth (2002), que aponta para diferentes maneiras nas quais interpretações escritas para gráficos são oferecidas no corpo do texto de livros didáticos canadenses e americanos para o

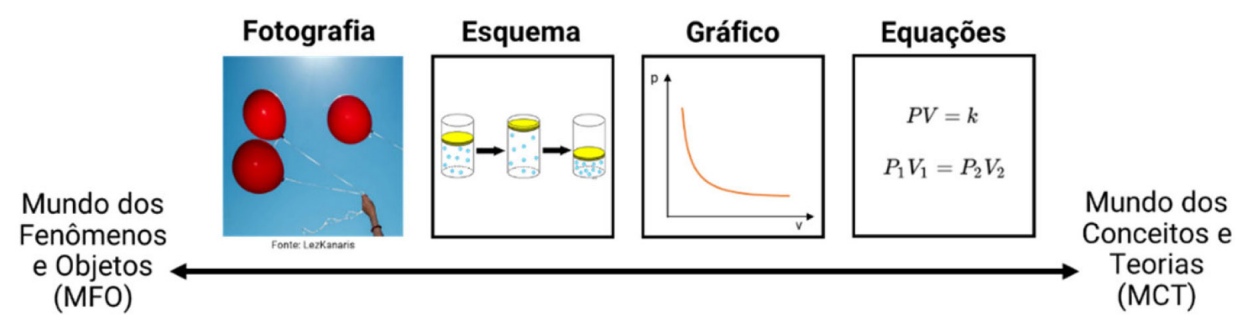

Figura 1: Cascata de inscrições relacionadas à lei de Boyle. Fonte: autoria própria. 
ensino de Ecologia, e de artigos originais de pesquisa da mesma área. Segundo os autores, estes artigos frequentemente incluem vários parágrafos que realizam um detalhamento e instrução minuciosa acerca da leitura de uma única inscrição, incentivando a sua compreensão. Já nos livros didáticos, menos recursos estão disponíveis, de maneira que aqueles dedicados ao ensino superior incluem algumas poucas sentenças, e os livros do ensino básico, em muitos casos, nem mencionam os gráficos.

\section{Legendas}

Simplesmente chamar a atenção dos leitores para as inscrições também não ajuda muito no processamento das mesmas (Slough et al., 2010). A partir disso, a legenda de uma inscrição é um dos principais recursos empregados por autores de textos científicos para reduzir a flexibilidade interpretativa e conectar a inscrição com o conteúdo abordado no corpo do texto, visto que ela fornece recursos adicionais para a leitura da inscrição. Adotamos aqui a concepção de Eco (2001), que entende o texto como qualquer entidade que possa ser interpretada. Assim, a legenda e a inscrição são dois conjuntos de sinais diferentes, ou dois textos diferentes, que, no entanto, não são independentes. Como as legendas sempre aparecem logo abaixo ou ao lado de uma inscrição, entende-se que as duas formas diferentes e arbitrárias de sinais estão diretamente associadas (Pozzer e Roth, 2003).

De acordo com a importância das legendas para uma boa interpretação das inscrições, pesquisas apresentam maneiras como estas são inseridas nos livros didáticos e outros textos científicos. Cita-se ainda o trabalho de Slough et al. (2010), que classifica legendas em quatro níveis: nível L0 - nenhuma legenda; nível L1 - legenda que identifica ou nomeia a inscrição, mas não fornece detalhes acerca da mesma; nível L2 - legenda que fornece uma descrição detalhada da inscrição, associando-a ao conteúdo abordado no corpo do texto; e nível L3 - legenda que envolve ativamente o leitor. Ao analisarem as inscrições presentes em quatro livros didáticos americanos destinados ao ensino de Ciências, os autores identificaram predominantemente legendas do tipo L1 $(38,9 \%)$ e L2 $(33,3 \%)$, além de serem identificadas porcentagens de inscrições sem legendas $(18,5 \%)$ e inscrições com legenda do tipo L3 (9,3\%). A respeito deste último tipo, as legendas que engajam o leitor são aquelas que fazem perguntas ou sugerem a execução de tarefas relacionadas à inscrição que gerem um produto examinável, como por exemplo, fazer com que os leitores rotulem recursos da representação (Slough et al., 2010), o que pode melhorar o engajamento do leitor com a inscrição e seu exame mais detalhado

Já o estudo de Pozzer e Roth (2003) desenvolveu um quadro analítico (Figura 2) que articula o corpo do texto, as inscrições, suas legendas e outros elementos, buscando descrever a natureza de suas relações na produção de sentidos.

Segundo os autores, todas as relações expressas entre as diferentes partes de um texto (corpo do texto, título, inscrições,

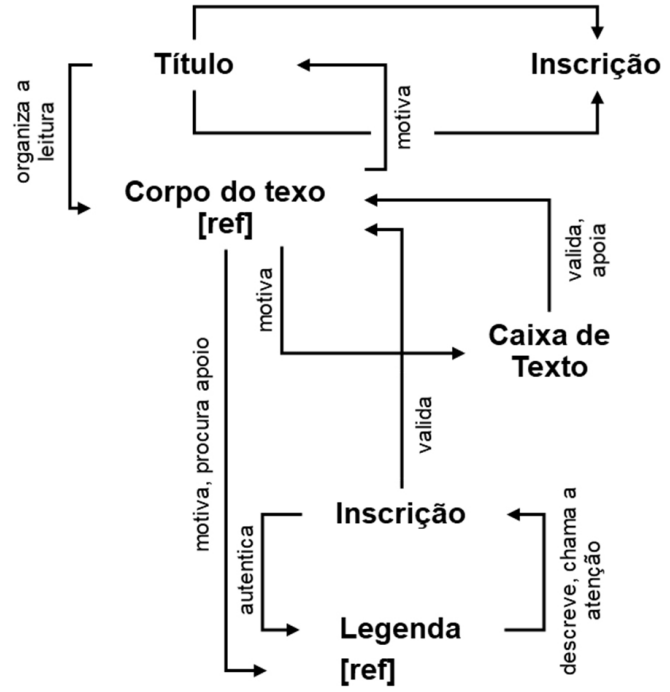

Figura 2: Quadro analítico para inscrições que acompanham textos científicos. Fonte: adaptado de Pozzer e Roth (2003).

legenda e caixa de texto) envolvem movimentos duplos. O título prepara o leitor para o que está por vir e, assim, organiza a leitura do texto. Porém, um título não é escolhido arbitrariamente, mas foi motivado pelo conteúdo do corpo do texto. Este último faz certas afirmações ou procura explicar um conceito que o motiva a utilizar uma inscrição particular. A inscrição, por sua vez, ao estar associada com o conceito explicado no corpo do texto, fornece evidências e valida as afirmações feitas nele. $\mathrm{O}$ corpo do texto e a legenda apontam ao leitor para o que olhar na inscrição, ensinando-o a lê-la. Dessa forma, a relação entre a inscrição e o texto (legenda e corpo do texto) é reflexiva, de modo que eles se restringem e obtêm suporte um do outro (Pozzer e Roth, 2003).

Ainda segundo Pozzer e Roth (2003), apesar da principal função da legenda ser auxiliar na compreensão e interpretação das inscrições, as informações contidas nelas variam. A partir disso, as relações que o aluno pode estabelecer entre a inscrição e os demais elementos do texto também se alteram, ou seja, essas variações influenciam nas interpretações das inscrições pelos estudantes e, portanto, no que podem aprender com elas. Essas variações mudam também a função da inscrição no texto, e os autores identificam quatro funções para as fotografias veiculadas nos livros didáticos de Biologia, durante a abordagem da temática Ecologia, que podem ser aplicáveis aos demais tipos de inscrições incorporadas em outros textos verbais escritos:

- decorativa: quando a inscrição não é mencionada no corpo do texto e não possui legenda;

- ilustrativa: quando a inscrição possui uma legenda que apenas nomeia o que está sendo representado, sem fornecer informações adicionais ao que está sendo explicado no corpo do texto;

- explicativa: quando a inscrição possui uma legenda que além de nomeá-la, provê explicações e classificações acerca do fenômeno ou objeto, representando e ampliando a compreensão do que está sendo abordado no texto; 
- complementar: quando a legenda da inscrição, além de nomeá-la, descrevê-la e classificá-la, contém informações que não estão disponíveis no texto.

Para Pozzer e Roth (2003), tais funções também definem aproximadamente uma hierarquia de valor informacional crescente para as inscrições. Por exemplo, explicar um conceito exige mais do que simplesmente ilustrar um conceito. As inscrições com maior valor informacional também fazem o que as de menor valor fazem. Com base nessa classificação os autores encontraram que as fotografias veiculadas nos livros didáticos analisados possuíam função predominantemente ilustrativa $(35,1 \%)$ e complementar $(31,1 \%)$. Foram ainda identificadas porcentagens de inscrições explicativas $(28,4 \%)$ e decorativas $(5,4 \%)$. Devido à predominância das inscrições ilustrativas, os autores consideraram que o verdadeiro potencial pedagógico das fotografias dos livros didáticos analisados não foi alcançado, visto que, nos casos em que as fotografias apresentam função ilustrativa, a mesma não é necessária, ou seja, elas são como um suplemento ao texto, adicionando uma especificidade ou o ilustrando.

\section{Indexação}

Devido aos diferentes requisitos necessários para realizar a leitura de um texto e de uma inscrição, outro aspecto que se faz importante para delimitar a produção de sentidos de inscrições, durante a sua inserção em textos científicos ou didáticos, é a indexação. Segundo Pozzer e Roth (2003), é necessário que a inscrição e sua legenda, além de abordarem a mesma temática, ou seja, estejam integrados semanticamente, também sejam indexadas, para que se alcance uma integração física.

Com a indexação, os leitores são encaminhados de um determinado local no texto principal para a inscrição e sua legenda. Este encaminhamento pode aparecer na mesma página ou em página diferente da inscrição e é estabelecido por meio de um índice, como por exemplo "Figura 2", "Fig. 2" ou "ver Fig. 2", onde uma cópia desta referência também pode ser encontrada na legenda da inscrição. Quando as inscrições não são referenciadas no corpo do texto, dificilmente os leitores irão se dirigir às mesmas e prestar atenção no que estão representando. Com isso, as inscrições se tornam elementos secundários às informações e argumentos desenvolvidos no texto.

Slough et al. (2010) abordam ainda a indexação e a proximidade da inscrição com o texto por meio do conceito de contiguidade espacial, como uma forma de contribuição para a efetividade de sua função ilustrativa. Segundo os autores, os estudantes possuem um melhor desempenho em suas atividades de leitura quando os textos e as inscrições são colocados próximos, ao invés de separados um do outro na página. A partir disso, Slough et al. (2010) apresentam a seguinte classificação para a contiguidade espacial de inscrições em um texto, considerando a distância entre o momento em que a inscrição é citada e o momento em que ela aparece no livro:
- descontínua: quando o texto não cita a inscrição;

- distal: quando é necessário virar uma página do livro para enxergar a inscrição após a sua citação;

- facial: quando a citação está em uma página oposta à inscrição;

- proximal: quando a citação está na mesma página que a inscrição;

- direta: quando a citação e a inscrição são adjacentes.

Com base nessa classificação, para a análise de livros didáticos do ensino de Ciências, Slough et al. (2010) encontraram que a maioria das inscrições se apresentava de maneira contínua com o corpo do texto, e a maioria delas possuía contiguidade proximal $(42,8 \%)$. As inscrições diretas possuíam uma frequência de $19,3 \%$. No entanto, uma grande porcentagem das inscrições se encontrava descontínua do corpo do texto (32,7\%), em especial nos tópicos de biociências $(43,1 \%)$. A presença de inscrições descontínuas obstaculiza o aproveitamento do seu potencial pedagógico e impede uma plena integração física entre as inscrições e o corpo do texto.

\section{Metodologia}

A análise das características das inscrições foi realizada com relação a livros didáticos de Química. Em relação à seleção dos primeiros, Vassão (2018) indica livros amplamente empregados em cursos de graduação em Química, na disciplina introdutória, usualmente denominada de Química Geral. O estudo indica os seguintes livros como os dois mais recorrentes: Princípios de Química, autoria de Peter Atkins e Loretta Jones, e Química: A Ciência Central, de autoria de Theodore Brown e colaboradores, sendo estas as obras selecionadas para o presente estudo, nas suas respectivas, quinta (Atkins e Jones, 2012) e nona (Brown et al., 2005) edição, doravante referidas apenas como LD1 e LD2, respectivamente.

O presente trabalho se configura como um recorte de uma pesquisa de doutorado que envolve a aplicação de atividades didáticas, pautadas no uso de inscrições, junto a alunos do segundo semestre do curso de Bacharelado em Química do Instituto de Química de São Carlos, da Universidade de São Paulo. A análise empreendida neste trabalho busca compreender as características das inscrições com as quais os alunos já possuíam contato, o que poderia fornecer subsídios para a construção das atividades didáticas mencionadas. A partir disso, foram consultadas as ementas das disciplinas obrigatórias dos três primeiros períodos do curso, sendo selecionados para análise os capítulos nos quais constavam os conteúdos indicados pelos documentos. Foram assim selecionados nove capítulos do LD1, com uma soma total de 393 páginas. Já para o LD2, foram selecionados treze capítulos, com um total de 392 páginas. Os capítulos são compostos por seções, com explicação do conteúdo, e exercícios, resolvidos ou não, geralmente concentrados ao seu final. Há ainda a presença de caixas de texto, onde são abordadas informações relacionadas ao conteúdo dos 
capítulos nos quais elas se inserem. As inscrições presentes nos exercícios não resolvidos foram desconsideradas das análises. As páginas referentes à seção de exercícios não resolvidos que se encontravam no final de cada capítulo dos livros didáticos não foram contabilizadas.

Como primeira etapa da análise, foram identificados e quantificados os tipos de inscrições existentes em cada texto, de acordo com a seguinte classificação: fotografia, desenho icônico, desenho esquemático, esquema de formulação, mapa, fluxograma, gráfico, tabela e equações. É importante ressaltar que conjuntos de inscrições que são indexadas pelo mesmo índice numérico, quando existentes, foram contabilizadas apenas uma vez, de acordo com o tipo predominante ou mais relevante. As inscrições foram catalogadas em planilhas do Microsoft Office Excel 2019 e categorizadas com base nas suas contiguidades físicas e tipos de legendas, de acordo com as classificações apresentada por Slough et al. (2010); na presença ou ausência de índices; e nas suas funções, de acordo com a classificação de Pozzer e Roth (2003). Esta etapa foi realizada pelos dois primeiros autores do presente artigo, que, em seguida, discutiram os aspectos da classificação frente aos quais haviam discordado, tendo em vista o alcance de um consenso.

Após esta etapa, os dados obtidos foram então discutidos com base nos referenciais teóricos apresentados nos tópicos anteriores. Cabe, por fim, ressaltar que a intenção desta análise não é apontar qual o melhor texto científico a ser utilizado no ensino superior de Química, mas discutir suas potencialidades e fragilidades, fornecendo assim aos autores e professores subsídios acerca de como elevar a capacidade pedagógica de inscrições em livros didáticos e durante a sua aplicação na sala de aula.

\section{Resultados e discussão}

Em relação a uma caracterização inicial e comparação entre os textos analisados, foram contabilizadas, no LD1, um total de 953 inscrições (média de 2,42 \pm 1,56 inscrições por página). Já no LD2, foram contabilizadas um total de 594 inscrições (1,52 $\pm 1,16$ inscrições por página). A partir dos valores de média identificados, é possível inferir que existe uma tendência dos autores do LD1 a utilizarem mais inscrições em seu texto, o que confere aos alunos que o utilizam uma maior possibilidade de contato com elas. Esta tendência diminui no LD2, de forma que o contato de inscrições ao se utilizar o texto é menor. A Tabela 1 apresenta a caracterização da distribuição geral dos tipos de inscrições nos textos analisados.

A Tabela 1 mostra que o tipo de inscrição mais presente no LD1 é o desenho esquemático (254 - 26,7\%), que possui uma recorrência média de 0,65 desenhos a cada página. Os valores apresentados na Tabela 1 revelam uma tendência para a presença de tipos de inscrições que segue a seguinte ordem no LD1: DES $>$ FOR $>$ GRA $>$ EXP $>$ FOT $>$ TAB $>$ ICN $>$ MAP = FLU. Já no LD2, o tipo de inscrição mais presente no texto são as fórmulas estruturais (138 - 23,2\%), que possuem uma recorrência de 0,35 inscrições por página. Os dados apresentados na Tabela 1 apontam que a presença de inscrições no LD2 segue a seguinte tendência: FOR $>$ DES $>$ FOT $>$ EXP $>$ TAB $>$ GRA $>$ ICN $=$ FLU $>$ MAP.

Ainda de acordo com a Tabela 1, em todos os textos, as inscrições com menor frequência são os mapas, os fluxogramas e os desenhos icônicos. Estes resultados estão de acordo com o que é encontrado na literatura, que também indica a escassez de mapas e fluxogramas em livros didáticos (Bowen e Roth, 2002; Slough et al., 2010). De maneira semelhante, os desenhos icônicos também não possuem recorrência na Química (Pazinato et al., 2016) e trabalhos reportam sua maior frequência em textos da área das Ciências Biológicas (Pozzer e Roth, 2003; Slough et al., 2010). É importante ressaltar que apesar dos fluxogramas serem comumente utilizados no ensino de Química para ilustrar procedimentos experimentais, estes são facilmente substituídos por desenhos esquemáticos.

Ainda com base nos valores reportados na Tabela 1, e em relação ao continuum das inscrições (Figura 1), observa-se que os textos possuem uma tendência na utilização de inscrições próximas ao MCT, visto que estas contabilizam $60,2 \%$ e 59,8\%, no LD1, LD2, respectivamente. Este fato não é surpreendente, já que o texto aborda conteúdos de Ciências da Natureza, que possui uma linguagem particular e própria, baseada especialmente no uso de fórmulas estruturais, além dos gráficos, tabelas e equações. A alta recorrência de desenhos esquemáticos nos livros didáticos revela ainda determinada harmonia em relação à quantidade de inscrições próximas ao MFO e ao MCT, o que se configura como um aspecto positivo. Ou seja, os livros

Tabela 1: Distribuição dos tipos de inscrições nos textos analisados.

\begin{tabular}{ccccccccccc}
\hline & & FOT & ICN & DES & MAP & FOR & GRA & TAB & FLU & EQA \\
\hline \multirow{3}{*}{ LD1 } & Tot $^{\mathrm{a}}$ & 103 & 20 & 254 & 2 & 233 & 144 & 56 & 2 & 139 \\
& $\%{ }^{\mathrm{b}}$ & $10,8 \%$ & $2,1 \%$ & $26,7 \%$ & $0,2 \%$ & $24,4 \%$ & $15,1 \%$ & $5,9 \%$ & $0,2 \%$ & $14,6 \%$ \\
& Ins/Pág $^{\mathrm{c}}$ & 0,26 & 0,05 & 0,65 & 0,01 & 0,59 & 0,37 & 0,14 & 0,01 & 0,35 \\
\hline \multirow{2}{*}{ LD2 } & Tot $^{\mathrm{a}}$ & 109 & 13 & 116 & 1 & 138 & 51 & 64 & 13 & 89 \\
& $\%^{\mathrm{b}}$ & $18,4 \%$ & $2,2 \%$ & $19,5 \%$ & $0,2 \%$ & $23,2 \%$ & $8,6 \%$ & $10,8 \%$ & $2,2 \%$ & $15,0 \%$ \\
& Ins/Pág $^{\mathrm{c}}$ & 0,28 & 0,03 & 0,30 & 0,00 & 0,35 & 0,13 & 0,16 & 0,03 & 0,23 \\
\hline
\end{tabular}

FOT: fotografia; ICN: desenho icônico; DES: desenho esquemático; MAP: mapa; FOR: fórmula estrutural; GRA: gráfico; TAB: tabela; FLU: fluxograma; EQA: equações;

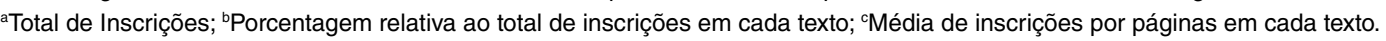


possibilitam o contato com inscrições de diferentes naturezas e que requerem diferentes esforços de leitura, o que fomenta $o$ desenvolvimento de habilidades necessárias para lidar com elas.

Verificada a distribuição das inscrições, é possível comparar os resultados com algumas pesquisas que analisam inscrições presentes em livros didáticos destinados ao ensino de Química de nível médio e verificam uma predominância de inscrições próximas ao MFO (Goes et al., 2018; Pazinato et al., 2016; Han e Roth, 2006). Por exemplo, Han e Roth (2006) utilizam uma classificação de inscrições semelhante àquela utilizada na presente pesquisa para a análise de nove livros didáticos, e encontram como resultado a presença de 2,24 inscrições por página, sendo verificada a predominância do uso de fotografias $(55,8 \%)$, desenhos icônicos (cartoons - 11,9\%) e esquemas de formulação $(10,3 \%)$. A predominância no uso de fotografias e inscrições próximas ao MFO em livros didáticos do ensino médio pode ser constatada também em estudos de outras áreas (Pozzer e Roth, 2003; Darroz et al., 2017).

Nessa perspectiva, é possível sugerir que a transição do nível médio para o nível superior do ensino de Química é acompanhada pelo incremento do contato dos estudantes com inscrições próximas ao MCT, o que aponta para a necessária atenção dos educadores e dos autores de livros didáticos dedicados a este nível de ensino em relação ao uso de inscrições com as quais até então os estudantes possuíam pouca intimidade. Além disso, com base nos diversos problemas que estes enfrentam, como por exemplo, baixa indexação e pouco uso de legendas (Han e Roth, 2006; Slough et al., 2010), é recomendável que investigações sejam levadas a cabo acerca de como as dificuldades dos mesmos acompanham o incremento de inscrições do MCT em livros didáticos, do ensino médio para o ensino superior.

É possível destacar ainda algumas relações a respeito do uso dos diferentes tipos de inscrições ao longo dos livros analisados. Segundo os autores do LD2, os cinco primeiros capítulos buscam oferecer "uma visão bastante macroscópica e fenomenológica da Química" (Brown et al., 2005, p. xiii). Nos demais capítulos alterna-se a discussão entre os diferentes níveis organizacionais da matéria. A partir disso, nos remetemos aos três níveis de representação do conhecimento químico propostos por Johnstone (1993; 2000): macroscópico, submicroscópico e representacional ou simbólico. O nível macroscópico compreende as experiências tangíveis, concretas e mensuráveis, ou seja, os fenômenos observáveis na sua forma empírica. O nível submicroscópico compreende as partículas atômicas, tais como átomos, moléculas, íons, elétrons etc. Já o nível simbólico corresponde aos símbolos, equações e fórmulas estruturais utilizadas para descrever e representar o conhecimento químico.

O desenvolvimento do conhecimento químico deve levar em consideração os três níveis propostos, e, assim, o conjunto de inscrições utilizadas para abordar determinado conceito ou conteúdo químico precisa integrar os três níveis e, dessa forma, facilitar o entendimento e aprendizado da Química (Goes et al., 2020; Upahi e Ramnarain, 2019).

Ao citar que nos primeiros capítulos é oferecida uma visão ainda macroscópica da Química, entendemos que o LD2 ainda não está transitando de maneira acentuada entre os níveis simbólico e submicroscópico, o que impulsiona a utilização de inscrições próximas ao MFO, como fotografias e desenhos, o que, segundo Upahi e Ramnarain (2019), é de fato esperado. A partir disso, é possível verificar que nos primeiros capítulos do LD2 o uso de gráficos, fórmulas estruturais e equações é reduzido. Tais tipos de inscrições caracterizam o nível simbólico e são utilizados com veemência quando é necessário "acessar" o nível submicroscópico, o que pode ser verificado à medida que se avança nos demais capítulos e ocorre um incremento no uso de inscrições próximas ao MCT do Capítulo 6 em diante.

É interessante notar que o mesmo padrão não é observado para o LD1, de maneira que a obra também integra inscrições que relacionam os três níveis representacionais de Johnstone (1993), porém, já nos capítulos iniciais é possível encontrar um alto número de inscrições próximas ao MCT, em especial, as fórmulas estruturais e as equações. Além disso, os desenhos esquemáticos, inscrições próximas ao MFO, se fazem altamente frequentes ao longo de todo o livro. Assim, seja de maneira gradual, como no LD2, ou com uma abordagem direta, como no LD1, ambas as obras podem potencializar o desenvolvimento de uma compreensão significativa de conceitos químicos e o desenvolvimento de modelos mentais para a compreensão de fenômenos.

Destaca-se ainda a observação da predominância no uso de determinados tipos de inscrições para a abordagem de conteúdos em ambos os livros. Relata-se inicialmente o uso predominante de fórmulas estruturais nos capítulos que tratam da estrutura eletrônica da matéria e da ligação química. Para o LD1, nos capítulos 2 e 3, foi possível identificar 50 e 73 fórmulas estruturais, respectivamente, que representam $51,5 \% \mathrm{e}$ $56,1 \%$ do total de inscrições neles presentes. Já no LD2, nos capítulos 8 e 9, foram catalogadas um total de 35 e 41 fórmulas estruturais, que representam $66,0 \%$ e $46,6 \%$ do total de inscrições daqueles capítulos, respectivamente.

A acentuada presença das fórmulas estruturais na abordagem dessas temáticas é reportada em outros estudos (Pazinato $e t$ al., 2016), e nos livros analisados se deve ao fato de o tratamento da temática ocorrer em torno das estruturas de Lewis, de maneira que cada livro dedica uma seção do texto para ensinar como desenhá-las, por meio de exercícios resolvidos que contemplam também estruturas de ressonância e cargas formais das moléculas, o que impulsiona e justifica a alta presença de inscrições do tipo fórmulas estruturais no capítulo. Destaca-se também, durante a abordagem das temáticas Geometrias Moleculares e Teorias de Ligação, a alta recorrência de fórmulas estruturais do modelo de bolas e varetas para representar as geometrias moleculares, além das representações das superfícies limites dos orbitais híbridos e orbitais moleculares. Concorda-se com 
Pazinato et al. (2016, p. 140) em relação à proeminência das fórmulas estruturais em livros didáticos, de maneira que "os LD sejam fonte deste tipo de representação, assegurando ao processo de ensino e aprendizagem ilustrações que proporcionem imaginar e discutir o nível submicroscópico em sala de aula".

É possível observar ainda uma alta recorrência no uso de equações durante a abordagem da temática Gases em ambos os livros didáticos, a qual ocorre nos capítulos 4 e 10 do LD1 e LD2, respectivamente, e possuem um total de 28 e 27 equações, que representam $30,1 \%$ e $48,2 \%$ do total de inscrições dos capítulos. O estudo da temática consiste na utilização de variáveis empíricas, tais como volume, pressão, temperatura e quantidade de gás, para descrição do comportamento da matéria no estado gasoso. Tais variáveis são relacionadas na forma de equações, como, por exemplo, as leis dos gases e a equação do gás ideal. A partir disso, o objetivo principal dos capítulos é apresentar a obtenção e uso dessas equações, além de outras como a lei de Dalton, lei da efusão de Graham e a equação de van der Waals, para descrever os gases, o que implica na inserção numerosa de diversas equações no capítulo.

Equações representam um recurso poderoso para os cientistas, que, segundo Alves (2011, p. 45), "criam, no contexto de uma ideologia determinista, a esperança de antecipar e controlar os fenômenos em uma escala nunca antes permitida". Este aspecto é observado durante a abordagem da temática Gases, já que as leis dos gases são mencionadas de imediato no início do capítulo 4 do LD1 e os autores seguem um roteiro didático que visa à obtenção e destaque dessas leis entre outras equações, o que demonstra a posição central das inscrições nesse contexto. Além disso, ao final do capítulo do LD1, são mencionados alguns conhecimentos que devem ser dominados pelos alunos, e que justificam a alta recorrência das equações durante a abordagem da temática, como por exemplo, "usar as leis dos gases para calcular $P, V, T$ ou $n$, em determinadas condições ou depois de uma mudança de condições" e "usar a equação de van der Waals para estimar a pressão de um gás" (Atkins e Jones, 2012, p. 163).

Apresenta-se, a seguir, a análise das características das inscrições e da maneira como foram inseridas no texto, ou seja, análise das suas contiguidades físicas, das suas legendas, da presença ou ausência de índices, e das suas funções. Ressalta-se que desse momento em diante as equações foram desconsideradas da análise visto que as classificações adotadas para as demais inscrições não são coerentes para a análise de equações. Por exemplo, para a análise das legendas das inscrições, de acordo com a classificação apresentada por Slough et al. (2010), as equações possuiriam legendas do tipo L0, ou seja, nenhuma legenda, o que resultaria em distorção da visualização geral acerca de como as demais inscrições estão apresentadas nos textos.

\section{Análise da contiguidade física}

A contiguidade física refere-se à proximidade da inscrição com a sua citação no corpo do texto, a qual pode ser classificada em descontínua, distal, facial, proximal e direta. A Figura 3 apresenta a contiguidade das inscrições nos textos analisados.

A partir dos resultados expressos na Figura 3, primeiramente, aponta-se um caráter positivo geral nos textos, devido à predominância de inscrições diretas e proximais, o que favorece o entendimento das inscrições e o desenvolvimento de habilidades de leitura e interpretação. A integração conceitual de uma inscrição com o seu corpo do texto recebe grande influência da sua integração física com o mesmo. Dessa forma, é desejável que inscrições sejam veiculadas na mesma página em que foram citadas, isto é, apresentem as contiguidades proximais ou diretas, que auxiliam, em uma maneira mais simples, no estabelecimento de relações e movimentos entre o texto verbal e a inscrição, o que pode melhorar a leitura do texto e das inscrições, ou seja, causar um aprendizado mais efetivo. A soma das inscrições diretas e proximais para o LD1 (87\%) e o LD2 (76\%) se aproxima daqueles encontrados por Nyachwaya e Gillaspie (2016), que durante a avaliação de cinco livros de Química destinados ao ensino superior, reportam valores entre $80 \%$ e $92 \%$. Considerando ainda os resultados expressos por Slough et al. (2010), tais comparações favorecem o entendimento de que os estudantes do ensino superior enfrentam menos dificuldades durante a integração física da inscrição com o corpo do texto.

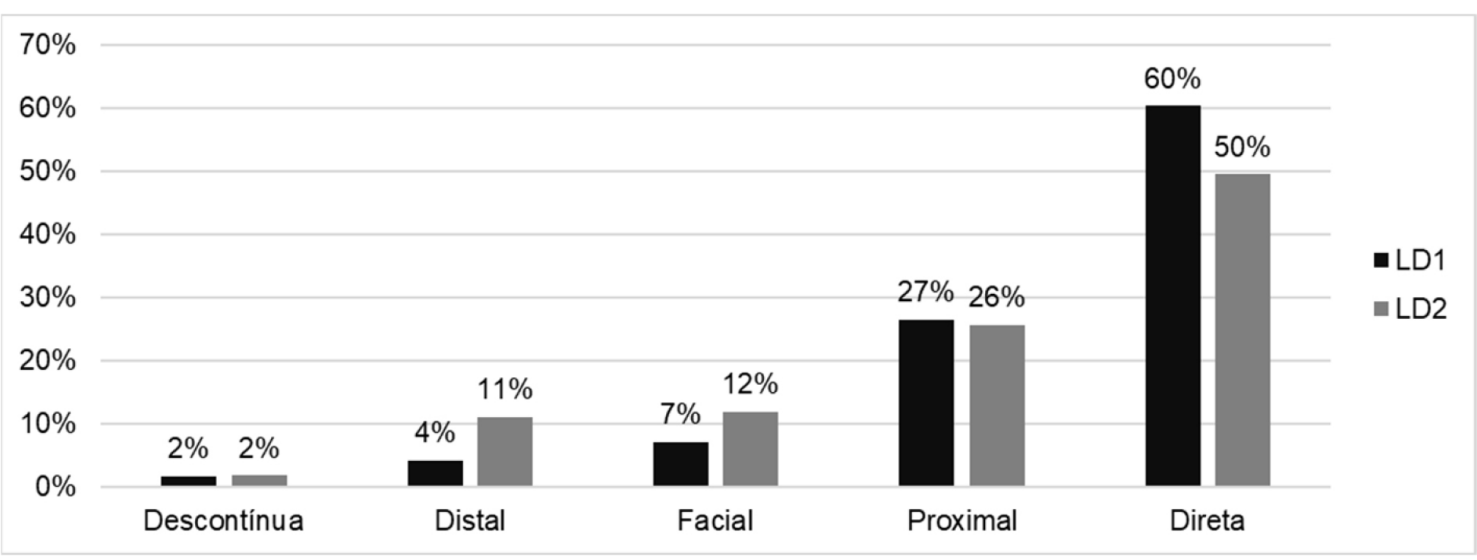

Figura 3: Distribuição das contiguidades das inscrições nos textos analisados. Fonte: autoria própria. 
Outro ponto a ser destacado é a baixa presença de inscrições descontínuas nos textos analisados, quando comparados com outros estudos (Slough et al., 2010). Em relação às inscrições descontínuas, faciais e distais, em concordância com Nyachwaya e Gillaspie (2016), entende-se que a presença dessas representa aos alunos a imposição de desafios de mobilidade e de leitura. Além disso, quando uma inscrição não é mencionada no corpo do texto ou quando o aluno precisa mudar de página para encontrá-la, a tendência é de que a representação passe despercebida, ou seja, as informações dela provenientes acabam por não serem efetivas para a construção do conhecimento. Outro aspecto relatado por Nyachwaya e Gillaspie (2016) para quando os alunos precisam mudar de página se refere à perda de concentração, visto que a mesma requer demasiado esforço cognitivo. De fato, McTigue e Slough (2010) orientam a não esperar que leitores folheiem as páginas de um texto para encontrar inscrições, pois, provavelmente, a maioria deles não fará esse esforço.

Entre os principais fatores que influenciam no posicionamento da inscrição no corpo do texto, um deles que se evidencia nesta pesquisa é o seu tamanho. Inscrições com um tamanho significativo dificilmente aparecerão imediatamente após serem citadas no corpo do texto, exibindo contiguidades geralmente do tipo proximal. Este é o caso da maioria das tabelas, que em todos os textos analisados apresentam contiguidade preferencialmente proximal, e ainda faciais ou distais, em especial para as tabelas presentes no LD2.

O layout da página se mostra como um último fator na contiguidade das inscrições. A Figura 4 apresenta os layouts das páginas dos textos analisados.

Segundo Gkitzia et al. (2011), os autores de inscrições e textos científicos devem prestar atenção à localização dos

a)

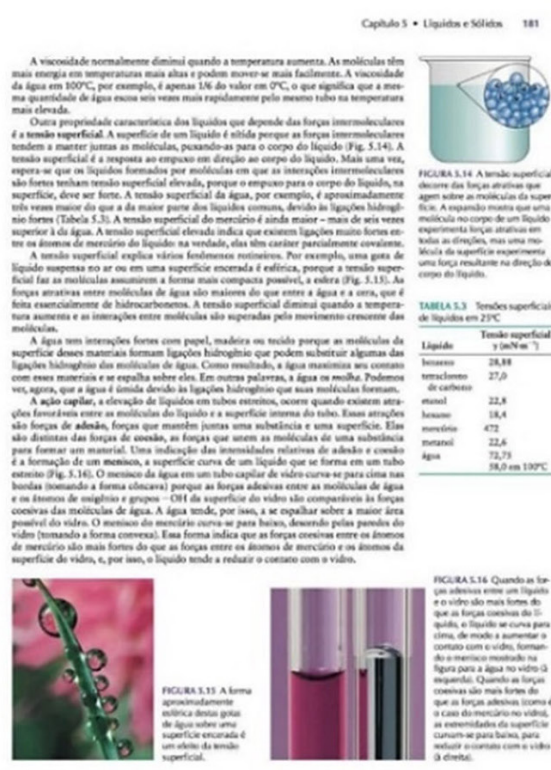

elementos verbais e visuais, de forma que é necessário um layout cuidadoso quando várias inscrições serão inseridas. Em relação à Figura 4, ressalta-se inicialmente que a sua inserção visa à mera comparação entre o posicionamento dos corpos de textos e das inscrições nas páginas dos livros analisados. Em relação ao layout do LD1 (Figura 4a), este se caracteriza por exibir um corpo do texto recuado para a esquerda ou para direita, de acordo com a paginação, ocupando cerca de $3 / 4$ da largura da página. Os demais $1 / 4$ correspondem a um espaço que os autores destinaram ao posicionamento das inscrições e suas respectivas legendas. Importante ressaltar que vazios no espaço das inscrições não são preenchidos com o corpo do texto, ou seja, mesmo que a página não possua inscrições, o texto não ocupa toda a largura da página. No LD1, as inscrições também podem ser alocadas nas margens superiores ou inferiores. Este layout favorece contiguidades diretas e proximais, visto que, por possuir um espaço específico para ser veiculada, ao ser citada no corpo do texto, a inscrição aparece, geralmente, logo ao lado do parágrafo em que é citada, ou seja, exibe contiguidade direta. Quando existem outras inscrições no espaço destinado às mesmas, a nova inscrição pode ser inserida distante do parágrafo em que foi citada, ou, dependendo do seu tamanho, ser veiculada na borda superior ou inferior, ou ainda na próxima página, o que ocasiona contiguidades proximais, faciais e distais.

Em relação ao layout do LD2, de acordo com a Figura 4b, este exibe um corpo do texto que ocupa preferencialmente toda a página. A partir disso, as inscrições e suas legendas são inseridas de acordo com o seu tamanho. Para inscrições de grande porte, existe a tendência de que as mesmas sejam inseridas nas margens superiores ou inferiores. Já as inscrições menores são geralmente inseridas dentro do próprio corpo do texto (como é

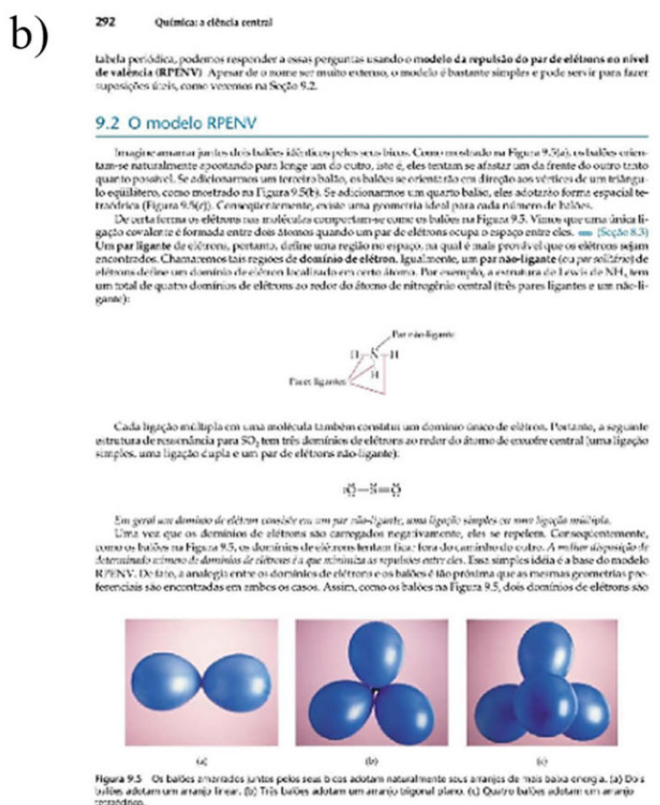


possível visualizar na Figura 4b), ou ainda nas margens esquerda ou direita, fazendo com que o texto seja rearranjado em volta da inscrição. A partir disso, entende-se que a predominância de contiguidades está relacionada com o tamanho da inscrição, de forma que as de grande porte usualmente exibem contiguidades proximais, faciais e distais, e as menores exibem contiguidades preferencialmente diretas e proximais.

\section{Análise das legendas}

A legenda de uma inscrição é um dos elementos mais importantes para a integração semântica, que pode ser entendida como a produção de sentido para a inscrição, a partir da sua conexão com o corpo do texto, ou seja, legendas podem facilitar ou dificultar o entendimento de uma inscrição (Slough et al., 2010). A Figura 5 apresenta os tipos de legendas das inscrições nos textos analisados.

Ressalta-se inicialmente um caráter positivo geral para os resultados encontrados, revelando que a maioria das inscrições está acompanhada de legendas, que podem promover o melhor entendimento das inscrições, assim como o desenvolvimento adequado de habilidades de leitura e interpretação. As porcentagens encontradas estão de acordo com outros estudos (Slough et al., 2010; Nyachwaya e Gillaspie, 2016). As legendas se fazem importantes pois, segundo Pozzer e Roth (2003), fornecem uma orientação instrucional aos alunos, informando-os sobre o que encontrar na representação e como interpretá-la.

A partir disso, ressalta-se que foram encontradas quantidades significativas de inscrições sem legendas nos livros didáticos analisados: 232 inscrições no LD1 $(28,5 \%)$ e 98 inscrições no LD2 (19,4\%). No estudo de Slough et al. (2010), os autores encontram que cerca de $18,5 \%$ das inscrições dos livros didáticos dedicados ao ensino de Ciências no nível fundamental não possuem legendas. Já Han e Roth (2006), durante a avaliação de nove livros de Química do ensino médio, relatam que cerca de metade das inscrições analisadas $(49,8 \%)$ não possuem legendas. Resultado semelhante é indicado por Gkitzia et al. (2011). Assim, entende-se que a falta de legendas em inscrições é um problema que os alunos enfrentam com os livros didáticos durante o seu ensino básico e permanecem quando os mesmos ingressam no ensino superior. A ausência da instrução fornecida pela legenda faz com que o aluno precise descobrir por conta própria qual o fenômeno que a inscrição está representando e quais os aspectos importantes que nela devem ser visualizados, o que, segundo Nyachwaya e Gillaspie (2016), eleva o esforço cognitivo, e consequentemente, dificulta a compreensão da temática.

Em relação à classificação das legendas de acordo com os tipos de inscrições, foi possível observar que fotografias e gráficos apresentam predominantemente legendas do tipo L2, em ambos os livros didáticos. Este tipo de legenda, além de nomear a inscrição, associa-a ao corpo do texto e ressalta ao leitor quais as características devem ser percebidas, o que a torna bastante interessante, em especial para as fotografias, as quais podem possuir detalhes gratuitos que facilmente desviam a atenção daquilo que deveria ser percebido. Para as fotografias, observa-se ainda a tendência de utilizar as legendas do tipo L2 para trazer informações extras que não estão presentes no corpo do texto, como por exemplo, fatos da história da Ciência, aplicações cotidianas, descrição detalhada de procedimentos experimentais etc.

Ressaltam-se ainda tendências encontradas para gráficos e tabelas. Apesar de não serem frequentes de maneira geral, as legendas L3 estão altamente associadas aos gráficos. Como mencionado anteriormente, legendas classificadas como L3 envolvem o leitor de maneira ativa na interpretação da inscrição. Já em relação às tabelas, observa-se o uso altamente predominante de legendas L1. Gráficos e tabelas geralmente possuem grande diversidade de dados, e a partir disso, instruções mais precisas sobre como enxergá-los, sobre como realizar comparação de dados, entre outras operações, são bem-vindas. Tais instruções só podem ser incorporadas por meio da utilização de legendas mais complexas, como L2 e L3, o que acontece para os gráficos, mas para as tabelas, as legendas do tipo L1 apenas nomeiam a representação, não auxiliando o leitor na realização dos processos citados.

As legendas L1 são interessantes para tabelas que são veiculadas com um caráter mais informativo e consultivo, como por exemplo, as tabelas com valores de constante ácida e alcalina,

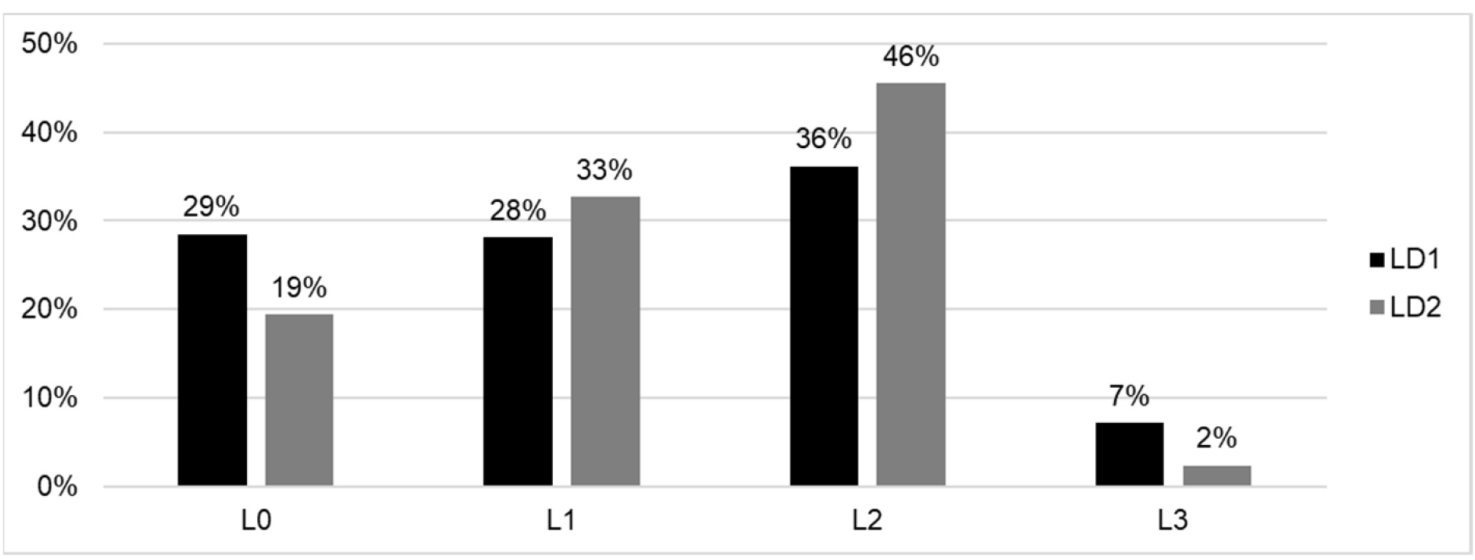

Figura 5: Distribuição dos tipos de legendas das inscrições nos textos analisados. Fonte: autoria própria. 
Pelo compartilhamento do par de elétrons ligante, cada átomo de cloro tem oito elétrons (um octeto) no nível de valência. Atingindo, assim, a configuração eletrônica de gás nobre do argônio.

As estruturas mostradas aqui para $\mathrm{H}_{2} \mathrm{e} \mathrm{Cl}_{2}$ são chamadas estruturas de Lewis (ou estruturas de pontos de elétrons de Lewis). Ao escrever as estruturas de Lewis, geralmente mostramos cada par de elétrons compartilhado entre os átomos como um traço e os pares de elétrons não compartilhados como pares de pontos. Escrevendo dessa forma, as estruturas de Lewis para $\mathrm{H}_{2} \mathrm{e} \mathrm{Cl}_{2}$ são mostradas como a seguir:

$$
\mathrm{H}-\mathrm{H} \quad \text { : }
$$

Figura 6: Fórmulas estruturais sem legendas no LD2. Fonte: Brown et al. (2005, p. 260).

nos livros didáticos. Ao utilizar uma legenda do tipo L1, pouca informação é adicionada pela mesma, assim o leitor pode direcionar seus esforços cognitivos para utilização e processamento dos dados informados. Já durante a inserção de uma tabela de caráter central, como aquelas que trazem resultados de um experimento, torna-se mais interessante a utilização de uma legenda mais complexa, que associe diretamente a inscrição ao corpo do texto, e que auxilie o leitor a encontrar na tabela o que o mesmo menciona, reforçando e justificando o discurso. No entanto, nota-se que são poucas as tabelas que apresentam legendas L2 ou L3.

Em relação às fórmulas estruturais, nota-se que no LD2 estão predominantemente desacompanhadas de legendas, de modo que dois fatores influenciam para tal resultado: posição da inscrição na página e número das inscrições. Primeiramente em relação à posição da inscrição na página, tomamos como exemplo a Figura 6.

No LD2 as fórmulas estruturais são geralmente inseridas de maneira direta dentro do espaço dedicado à explicação do conteúdo, como demonstrado na Figura 6. O corpo do texto anterior à inscrição geralmente prepara o leitor para o que irá visualizar, nomeando e fornecendo outros detalhes da fórmula estrutural, o que diminui a necessidade de legendas para as fórmulas estruturais que são inseridas dessa maneira.

Em comparação com o LD1, neste último as fórmulas estruturais raramente são inseridas dentro do corpo do texto, sendo encontradas no espaço dedicado a elas, e os autores utilizam de índice e legenda para que o leitor consiga associá-las ao corpo do texto. A partir disso, é possível observar uma frequência menor de fórmulas estruturais sem legendas no LD1 (26,6\%) em relação ao LD2 $(51,4 \%)$. Cabe ressaltar que a inserção de fórmulas estruturais ao longo do corpo do texto não impossibilita totalmente a exclusão das legendas.
Em relação ao número de fórmulas estruturais, a Tabela 1 mostra que há uma grande quantidade desse tipo de inscrição em ambos os livros. Entende-se que, na perspectiva de Cook (2006), apesar das legendas L2 e L3 auxiliarem o leitor no melhor entendimento das inscrições, elas também adicionam material extra a ser processado cognitivamente pelos alunos. Dessa forma, se a grande maioria das fórmulas estruturais no LD2 e no LD1 apresentassem legendas complexas, se exigiria do leitor uma alta demanda cognitiva, devido à abundância desse tipo de inscrição. A partir disso, a inserção destas dentro do espaço do texto (Figura 4) favorece a eliminação das legendas, e se mostra como uma característica positiva, já que possibilita menos esforço cognitivo para o leitor devido à redução de altas quantidades de material extra.

No LD1, as fórmulas estruturais estão acompanhadas predominantemente de legendas do tipo L1 $(46,4 \%)$. A presença de legendas L2 ou L3 para essas inscrições ocorre em momentos oportunos, quando é preciso chamar atenção do leitor sobre como visualizá-las. Uma vez feito isso, entende-se que adicionar legendas complexas em numerosas inscrições é um ato redundante que, segundo Cook (2006), deve ser evitado, para que este material extra não interfira no processo de aprendizagem do conteúdo que está sendo abordado. Assim, a utilização das legendas L1 para uma vasta quantidade de inscrições inseridas nas margens da página é um aspecto positivo para o livro.

\section{Análise da indexação}

A conexão entre o corpo do texto e uma inscrição é geralmente realizada por meio de um índice, presente no texto e na legenda da inscrição. A Figura 7 apresenta a porcentagem de inscrições com e sem índice nos textos analisados. Para a sua construção, as equações foram consideradas. Nas demais

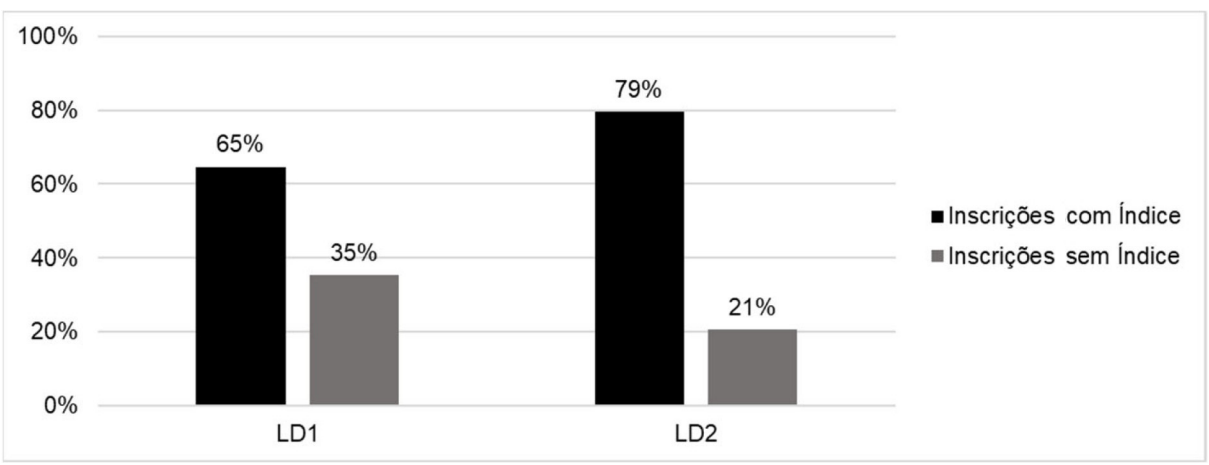

Figura 7: Porcentagens de inscrições com e sem índice nas obras analisadas. Fonte: autoria própria. 
análises tais inscrições não se faziam presentes visto que os referenciais adotados para análise não se adequavam às mesmas. Foram consideradas como indexadas as inscrições que possuíam índice simultaneamente disponível na legenda da inscrição e no corpo do texto.

A Figura 7 mostra que a maioria das inscrições, em todos os textos, possui índices. Ressalta-se a existência de uma parcela significativa de inscrições sem índices: $35 \%$ no LD1 e $21 \%$ no LD2. Estas inscrições compreendem majoritariamente àquelas associadas a exercícios resolvidos dentro dos capítulos do LD1, e àquelas inseridas dentro do espaço textual, em especial, as fórmulas estruturais, no LD2.

Em relação a outras pesquisas que analisam livros didáticos dedicados ao ensino superior de Química, citamos os resultados de Nyachwaya e Gillaspie (2016), que encontram porcentagens de ausência de indexação diversas (entre 5\% e $39 \%$ ) durante a avaliação de cinco livros, as quais abrangem os valores encontrados nesta pesquisa. Já em relação ao ensino básico, pesquisas como as de Slough et al. (2010), Gkitzia et al. (2011) e Han e Roth (2006) relatam porcentagens semelhantes ou maiores de inscrições não indexadas. Isto sugere que a falta de indexação é um problema que alcança o ensino de Ciências e de Química desde o ensino fundamental, passando pelo ensino médio até o superior.

Em relação à maneira da construção do índice, no LD2 ela ocorre de forma consistente ao longo dos textos, de forma contínua com o texto, ou ainda com inserções de parênteses, que pode ocorrer tanto no meio do texto ou ao final do parágrafo, sem a ocorrência de abreviações. Já no LD1, percebe-se que não há consistência na construção dos índices, sendo utilizadas abreviações ou termos completos para inserções contínuas com o texto ou com parênteses, com maior ocorrência desta última.

A forma como o índice é construído pode interferir no modo como a inscrição é percebida pelo leitor. Segundo Pozzer e Roth (2003), quando o índice é colocado imediatamente após uma palavra ou dentro/após uma frase que é cotemática com a legenda da inscrição, ou seja, que está falando exatamente do que está sendo representado na inscrição, é estabelecido um vínculo direto. Por exemplo, na Figura 8, o índice "(Fig. 1.2)" está localizada logo após a expressão "tubo de vidro sob vácuo", o que auxilia o leitor na associação e criação de um vínculo direto entre o termo e aquilo que está representado na "Figura 1.2" ao lado. Ou seja, o conjunto corpo do texto-índice-legenda-inscrição conta para o leitor que o que ele está observando representa um tubo de vidro sob vácuo.

Por outro lado, se o índice for colocado no final de um parágrafo que apresenta múltiplos conceitos, o vínculo não será mais direto, o que, segundo Pozzer e Roth (2003), pode interferir no processo de produção de sentidos e interpretação da inscrição já que há possibilidades de o leitor associar espontaneamente a inscrição com o último termo ou frase, que podem não corresponder exatamente ao que está colocado no texto. Ainda segundo os autores, o processo de criação de vínculo e interpretação da inscrição se torna ainda mais difícil quando ela está localizada em páginas diferentes daquela em que foi indexada, ou seja, apresenta contiguidades faciais, distais ou descontínuas. Pozzer e Roth (2003) apontam que o gerenciamento das páginas atrapalha na criação do vínculo, de forma que mesmo com legendas, as inscrições acabam por apresentar funções decorativas ao invés de outras funções mais informativas.

\section{Análise das funções das inscrições}

A função de uma inscrição diz respeito ao seu vínculo com o texto no qual ela está inserida, e surge com base na relação estabelecida entre a legenda da representação e o corpo do texto, podendo também receber influência da sua contiguidade física e da presença ou ausência de índices. Pozzer e Roth (2003) sugerem quatro funções para uma inscrição inserida em um texto científico: decorativa, ilustrativa, explicativa e complementar. A Figura 9 apresenta a distribuição das funções de inscrições nos textos analisados.

Com base nos resultados expressos na Figura 9, nota-se que os valores encontrados corroboram aqueles de Slough et al. (2010) e Nyachwaya e Gillaspie (2016), que reportam a predominância de inscrições com a função denominada representacional, análoga à função ilustrativa de Pozzer e Roth (2003). Observam-se ainda valores significativos de inscrições explicativas em todos os textos analisados, e inscrições complementares em maiores quantidades que as decorativas nos livros didáticos. Assim, de maneira geral, os textos apresentam

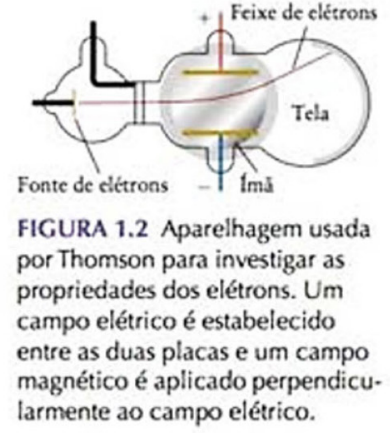

\subsection{Modelo nuclear do átomo}

A primeira evidência experimental da estrutura interna dos átomos foi a descoberta, em 1897, da primeira partícula subatômica, o elétron. O físico britânico J. J. Thomson (Fig. 1.1) investigava os raios "catódicos", os raios emitidos quando uma grande diferença de potencial (uma alta voltagem) é aplicada entre dois contatos de metal, chamados de eletrodos, em um tubo de vidro sob vácuo (Fig. 1.2). Thomson mostrou que os raios catódicos são fluxos de partículas negativas. Eles vêm do interior dos átomos que compõem o eletrodo com carga negativa, chamado de catodo. Thomson descobriu que as partículas carregadas, que depois foram chamadas de "clétrons", eram as mesmas, independentemente do metal usado no catodo. Ele concluiu que elas faziam parte de todos os átomos.

Figura 8: Exemplo de indexação que auxilia na associação do texto com a inscrição. Fonte: Atkins e Jones (2012, p. 2). 


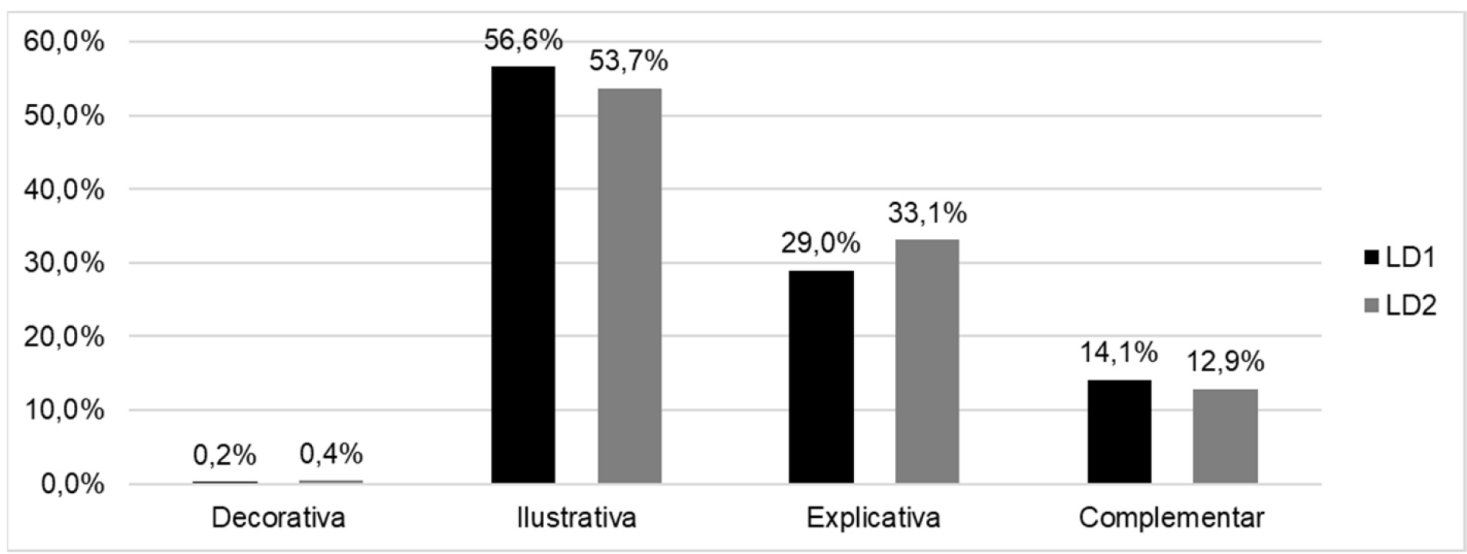

Figura 9: Distribuição das funções das inscrições nos textos analisados. Fonte: autoria própria.

aspectos positivos em relação à presença predominante de inscrições que auxiliam os estudantes no entendimento dos conteúdos associados, além de evidenciarem os diferentes papéis das inscrições para a Ciência.

Em relação às inscrições decorativas, durante a avaliação de livros didáticos de Ciências do ensino básico, Slough et al. (2010) encontram uma frequência de inscrições desse tipo no valor de 33,3\%. Já Nyachwaya e Gillaspie (2016), ao avaliarem outros livros didáticos dedicados ao ensino superior de Química, encontram frequências de inscrições decorativas com valores entre $5 \%$ e $14 \%$. Estes resultados sugerem a melhora dos aspectos relacionados ao valor informacional das inscrições utilizadas no ensino de Química durante a transição do ensino básico para o ensino superior. Os autores comentam que as inscrições decorativas são consideradas materiais extras e redirecionam para si os recursos cognitivos de leitura e avaliação, que deveriam ser aplicados no aprendizado da temática associada, ou seja, estas inscrições devem ser evitadas no texto.

Os textos avaliados nesta pesquisa possuem frequências de inscrições decorativas menores que $2 \%$. A partir disso, a baixa frequência dessas inscrições evidencia um aspecto favorável para a promoção de habilidades de leitura e interpretação de inscrições. No entanto, é importante ressaltar que as inscrições decorativas não são necessariamente ruins, ou seja, elas podem ser incluídas nos textos científicos em momentos oportunos e de maneira consciente. Dessa forma, autores dos livros didáticos precisam ter conhecimentos dos impactos desse tipo de inscrição na leitura do texto e no entendimento do conteúdo.

Uma situação particular e recorrente chama a atenção em relação ao modo como inscrições decorativas são inseridas ao longo dos textos analisados. Os critérios iniciais de Pozzer e Roth (2003) para classificar inscrições como decorativa consideram que elas não devem ser citadas no corpo do texto e nem possuir legendas. Posteriormente, os autores identificam que inscrições que estão distantes fisicamente do local em que são indexadas, isto é, são descontínuas, mesmo que possuam legendas, possuem uma função que não é diferente da decorativa. Em Pozzer e Roth (2003), o primeiro critério prevalece. Já na presente pesquisa, prevalece o segundo critério, o que aponta para descuido dos autores quanto ao posicionamento da inscrição, que eram classificados como decorativas por se encontrarem geralmente distante do local em que eram citadas. Inscrições localizadas em duas ou mais páginas do local em que foram indexadas se tornam decorativas visto que a maioria dos leitores provavelmente não irá folhear as páginas de um texto para encontrá-las (McTigue e Slough, 2010), e a partir disso, as informações contidas nelas em relação ao conteúdo abordado no corpo do texto não conseguem contribuir substancialmente para a sua compreensão.

Foi possível verificar a predominância das inscrições ilustrativas em todos os textos. Estas inscrições, segundo Pozzer e Roth (2003), são importantes para o entendimento da temática em estudo, pois constituem para o leitor um recurso visual concreto e exemplificador de um conceito que é representado. Verificado o número elevado de fórmulas estruturais nos livros didáticos, o uso de legendas mais simples se faz interessante para que o texto não exija alta demanda cognitiva do leitor, no entanto, isso reduz a função da inscrição à ilustrativa.

Vale ressaltar também que as inscrições que não possuem legendas, mas que possuem proximidade física com o texto, como por exemplo as inscrições associadas com exercícios resolvidos e as fórmulas estruturais de Lewis no LD2, também foram classificadas como ilustrativas, sendo esses os dois critérios mais relevantes para a classificação de inscrições dessa forma. A Figura 10, por exemplo, apresenta uma inscrição sem legenda no LD1 que foi classificada como ilustrativa.

Como descrito anteriormente, o LD1 possui um espaço específico destinado às inscrições. Porém, aquelas dos exercícios resolvidos não eram adicionadas nesse espaço, mas logo ao lado do passo do exercício que buscavam ilustrar, como é possível visualizar na Figura 10, o que revela uma relação física da inscrição com o texto. Han e Roth (2006) comentam acerca da existência de um padrão em livros didáticos do ensino de Química, que se refere à separação de determinadas seções, tais como caixas de textos, exercícios, manipulações matemáticas e procedimentos experimentais, ou seja, as seções diferentes daquelas destinada a explicação de conteúdos, por meio de linhas, caixas, fundos de cores diferentes. No LD1, 


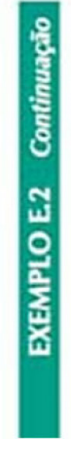

PLANEJE Para encontrar a quantidade de mols, divida a massa total da amostra pela massa molar.

\section{RESOLVA}

(a) De $n=m / M$,

$$
\begin{aligned}
n(\mathrm{~F}) & =\frac{22,5 \mathrm{~g}}{19,00 \mathrm{~g} \cdot(\mathrm{mol} \mathrm{F})^{-1}}=\frac{22,5}{19,00} \mathrm{~mol} \mathrm{~F} \\
& =1,18 \mathrm{~mol} \mathrm{~F}
\end{aligned}
$$

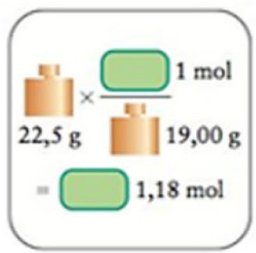

Avalie Como esperado, mais de $1 \mathrm{~mol}$ de $\mathrm{F}$ está presente.

Figura 10: Esquema com função ilustrativa no LD1. Fonte: Atkins e Jones (2012, p. F40).

por exemplo, a seção de exercícios resolvidos, ilustrada na Figura 10, é indicada pela existência de uma barra verde na lateral da mesma. Já no LD2, os exercícios resolvidos inseridos ao longo dos capítulos são apresentados em caixas de textos delimitadas por um fundo amarelo. É esta distinção que dá origem à percepção de uma proximidade entre as inscrições e o corpo do texto. O uso de recursos visuais para delimitar seções, segundo Han e Roth (2006), funciona como uma espécie de indexação, conectando a inscrição dentro daquela seção separada com a parte específica do corpo do texto que se refere. A partir disso, o leitor pode facilmente assumir que a inscrição busca representar o que está escrito no texto ao lado. Processo semelhante acontece quando visualizamos uma inscrição e a sua legenda, onde não há indicativos de que esses elementos de diferentes naturezas (imagética e textual) estão relacionados, mas devido à proximidade física de ambos, assumimos que eles estão (Pozzer e Roth, 2003).

Com base nessa proximidade, as inscrições associadas com os exercícios foram classificadas como ilustrativas. Por exemplo, ao visualizar o esquema presente na Figura 10, o leitor pode facilmente identificar que este busca representar graficamente o cálculo matemático descrito. Esta associação pode ser facilmente realizada não apenas devido à proximidade física da inscrição com o texto, mas também pela visualização dos valores numéricos e unidades de medidas em ambos o exercício e o esquema.

Nota-se que, em relação às tabelas, estas inscrições apresentam função predominantemente ilustrativa, devido ao uso de legendas que apenas nomeiam a inscrição. Visto que as funções das inscrições também representam uma ordem informacional (Pozzer e Roth, 2003), e sendo as tabelas inscrições com grande quantidade de dados a serem visualizados e comparados, surge um alerta em relação ao uso acentuado de tabelas com função ilustrativa. O uso de legenda mais informativas, que elevariam a função das tabelas, são bem-vindas, já que podem ensinar ao leitor maneiras de utilizá-las, apresentar fatores importantes para serem levados em consideração durante o uso dos seus dados, em especial nos livros didáticos.

Os gráficos possuem função predominantemente explicativa, o que se configura como um aspecto positivo. A Figura 11 apresenta um exemplo de gráfico com tal função.

A Figura 11 apresenta um gráfico do tipo curva de aquecimento para substâncias puras. A inscrição contém uma legenda do tipo L2. No texto, os autores definem curva de aquecimento como um gráfico de temperatura do sistema versus quantidade de calor adicionado, chamando imediatamente a figura por meio da disponibilização de um índice no texto e na legenda da inscrição (Figura 11.19), de maneira que o leitor é direcionado
Figura 11.19 Curva de aquecimento para a transformação de $1,00 \mathrm{~mol}$ de água de $-25^{\circ} \mathrm{C}$ para $125^{\circ} \mathrm{C}$ a pressão constante de $1 \mathrm{~atm}$. As linhas azuis mostram o aquecimento de uma fase de temperatura mais baixa para outra de temperatura mais alta. As linhas vermelhas mostram a passagem de uma fase para outra a temperatura constante.

\section{ATIVIDADE}

Curvas de aquecimento

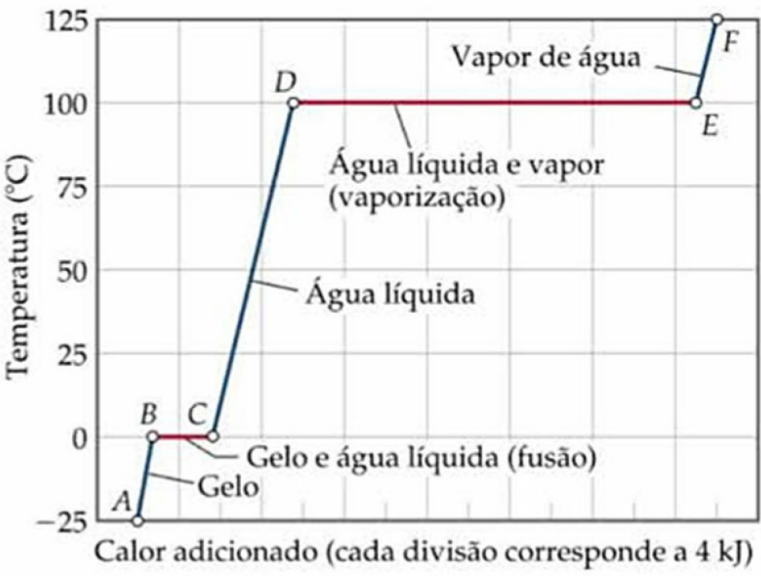

Figura 11: Gráfico com função explicativa no LD2. Fonte: Brown et al. (2005, p. 388). 
Os trabalhos de Plancke Einstein abriram caminho para a compreensão de como os elétrons são distribuídos nos átomos. Em 1913 o físico dinamarquês Niels Bohr (Figura 6.8) propôs uma explicação teórica dos espectros de linhas, outro fenômeno que intrigava os cientistas no século XIX. Vamos a princípio examinar esse fenômeno e, em seguida, estudar como Bohr usou as idéias de Planck e Einstein.
Figura 6.8 Niels Bohr (à direita) com Albert Einstein. Bohr

(1885-1962) fez importantes

contribuiçōes para a teoria

quântica. De 1911 a 1913 estudou na Inglaterra, trabalhando primeiro com I. I. Thomson, na Universidade de Cambridge, e mais tarde com Ernest Rutherford, na Universidade de Manchester. Publicou sua teoria quântica do átomo em 1914 e recebeu o Prêmio Nobel de Física em 1922.

Figura 12: Fotografia com função complementar. Fonte: Brown et al. (2005, p. 188).

para a mesma. O trecho inicial da legenda, "curva de aquecimento para a transformação de 1,00 mol de água de $-25^{\circ} \mathrm{C}$ para $125^{\circ} \mathrm{C}$ a pressão constante de $1 \mathrm{~atm}$ ", nomeia a figura e permite assim a imediata associação entre o que está sendo representado e o que estava sendo abordado no conteúdo, ou seja, disponibiliza para o leitor uma imagem de uma curva de aquecimento. Em seguida, a legenda traz instruções ao aluno sobre como observar o gráfico, indicando os aspectos a serem notados: as linhas azuis representam etapas de aumento de temperatura sem mudança de fase, e as linhas vermelhas, etapas de mudanças de fase sem aumento de temperatura. É importante observar que ao retornar ao corpo do texto, o leitor obtém uma discussão de outros aspectos do gráfico, como por exemplo, a caracterização do que cada segmento de curva no gráfico representa fisicamente, de maneira semelhante ao que ocorre em artigos originais de pesquisa, quando estas inscrições são utilizadas nos resultados, o que demonstra a possibilidade de um uso mais rico e informativo dessas inscrições.

Por fim, destacam-se as fotografias, que são o tipo de inscrição mais recorrente para a função complementar, no LD1 e no LD2. Esses resultados corroboram com aqueles encontrados por Pozzer e Roth (2003), que apresentam altos índices de presença de fotografias complementares em livros didáticos. As inscrições foram assim classificadas visto que apresentam uma legenda com informações que até então não estavam disponíveis no texto e enriquem o seu valor informacional, como exemplifica a Figura 12.

A Figura 12 traz um trecho do LD2 utilizado para introduzir a seção sobre o modelo de Bohr, indicando para o leitor a visualização da Figura 6.8, uma fotografia na qual é possível visualizar dois homens. A legenda da inscrição nomeia os indivíduos, sendo o da direita Niels Bohr e o da esquerda Albert Einstein. O restante da legenda adiciona informações extras sobre a carreira acadêmica do primeiro, disponibilizando para o leitor sua principal contribuição para a Química. Como estas informações não estão disponíveis no corpo do texto, a fotografia foi classificada como complementar.

\section{Considerações finais}

No presente trabalho investigamos as características das inscrições presentes em livros didáticos usualmente empregados por graduandos em Química no Brasil. A partir da caracterização da distribuição dos tipos de inscrições em dois livros didáticos, estas foram analisadas com base nas suas contiguidades físicas, tipos de legendas que as acompanham, presença ou ausência de índice e função da inscrição.

Os resultados mostraram que os textos analisados possuem em média, aproximadamente, duas inscrições por páginas, sendo elas em sua maioria inscrições próximas ao MCT, ou seja, inscrições que possuem pouca semelhança com os fenômenos e objetos que procuram representar e alto nível de abstração, a saber: fórmulas estruturais, gráficos, tabelas, fluxogramas e expressões algébricas. Estas observações corroboram com a natureza abstrata da linguagem representacional Química e a tendência do uso dessas inscrições em textos voltados para o público científico, sendo estes também os principais tipos de inscrições que os estudantes manipularão em sua carreira acadêmica e profissional, o que põe em foco a necessidade de atenção especial para como as mesmas são inclusas e veiculadas, não apenas nos textos científicos, mas também na sala de aula.

Apesar da predominância das inscrições próximas ao MCT, dentre as inscrições próximas ao MFO, que são aquelas que guardam semelhança com o que está sendo representado, se destacam os desenhos esquemáticos e as fotografias. Assim, a diversidade de tipos de inscrições observadas nos textos analisados corrobora a natureza multirepresentacional da Química.

No que diz respeito às maneiras como as inscrições estão integradas nos textos, foi possível observar que elas estão, em sua maioria, integradas de maneira direta ou proximal, ou seja, imediatamente disponíveis ao leitor logo após serem citadas no texto, ou em uma relação de proximidade física evidente. Além disso, é notável também o uso proeminente de índices. Ambas as características diminuem os esforços cognitivos necessários para o estabelecimento de um vínculo entre a inscrição e o conteúdo abordado.

Aliadas a essas características, a utilização de legendas nas inscrições se faz de maneira abundante. Em especial nos livros didáticos, as legendas não apenas nomeiam as inscrições, como também contêm instruções acerca da manipulação e visualização do que nelas está representado. Com respeito às funções das inscrições nos textos analisados, verificou-se a predominância de inscrições ilustrativas, que se constituem como um recurso visual importante para a exemplificação e a concretização de conceitos estudados. Sendo verificado um desequilíbrio entre a frequência das funções ilustrativas e explicativas, surge um alerta relacionado ao valor informacional das inscrições 
inseridas nos textos analisados e de que o seu verdadeiro potencial pedagógico e informativo não é plenamente alcançado. As inscrições explicativas não apenas desempenham um papel importante na representação do conhecimento químico, mas também no aprimoramento da compreensão deste conhecimento, complementando e dando suporte ao texto, e apresentam ao leitor a sua importância para a Ciência.

Ressaltam-se ainda algumas situações peculiares que chamaram a atenção durante a análise, tais como a predominância de tabelas com função ilustrativa e com legendas pouco informativas nos textos analisados; e quantidades significativas de inscrições sem legendas e mal indexadas nos livros didáticos. Estas situações representam os principais obstáculos com os quais os alunos devem lidar durante a utilização dos textos científicos em questão, caracterizando-se como barreiras ao desenvolvimento adequado de habilidade de leitura e interpretação requeridas para a melhor manipulação das próprias inscrições.

De fato, existem dentro das classificações utilizadas para análise das inscrições categorias que representam deficiências e obstáculos; especificamente, inscrições descontínuas, sem legendas, mal indexadas e com função decorativa, que apontam para um conteúdo instrucional deficiente. A partir disso, autores de livros didáticos precisam estar atentos à maneira como a inscrição será veiculada, para que esta seja confortável ao leitor e potencialize o seu entendimento. Os professores e educadores precisam ainda se atentar a tais características, identificando as potencialidades e fragilidades das inscrições presentes nos textos utilizados na sala de aula, de maneira que possam ser encontrados meios para suprimir as deficiências e fomentar as potencialidades.

\section{Agradecimentos}

À Fundação de Amparo à Pesquisa do Estado de São Paulo (Processo 2018/23809-3; Processo 2018/23819-9) e ao Conselho Nacional de Desenvolvimento Científico e Tecnológico (Processo 304974/2020-0) pelo apoio financeiro.

\section{Referências}

ALVES, E. G. Um estudo multimodal de textos didáticos sobre o efeito fotoelétrico. Dissertação (Mestrado). Universidade Federal de Minas Gerais, Belo Horizonte, 2011.

ATKINS, P. e JONES, L. Princípios de química: questionando a vida moderna e o meio ambiente. 5. Ed. Porto Alegre: Bookman Editora, 2012

AUTOR, 2020. Inserir referência completa.

BEDIN, E. Uma proposta e cinco análises de livros didáticos de química do ensino médio. Revista Areté, v. 12, n. 25, p. 183-201, 2019.

BIANCO, A. A. G. e MELONI, R. A. O Conhecimento escolar: um estudo do tema Diagrama de Linus Pauling em livros didáticos de química-1960/1970. Química Nova na Escola, v. 41, n. 2, p. 148$155,2019$.
BOWEN, G. M. e ROTH, W. M. Why students may not learn to interpret scientific inscriptions. Research in Science Education, v. 32, n. 3, p. 303-327, 2002.

BRASIL. Conselho Nacional de Educação. Parecer CNE/CES 1.303/2001, de 6 de novembro de 2001. Diretrizes Curriculares Nacionais para os Cursos de Química. Brasília: Diário Oficial da União, 2001.

Ministério da Educação. Secretaria de Educação Básica. Base Nacional Comum Curricular. Brasília: MEC, SEB, DICEI, 2019.

BROWN, T. L.; LEMAY Jr, H. E.; BURSTEN, B. E. e BURDGE, J. R. Química: a ciência central. 9. Ed. Campinas: Pearson Education, 2005.

CASSIANO, K. F. D. e ECHEVERRÍA, A. R. Abordagem ambiental em livros didáticos de Química: princípios da carta de Belgrado. Química Nova na Escola, v. 36, n. 3, p. 220-230, 2014.

CANZIAN, R. e MAXIMIANO, F. A. Princípio de Le Chatelier o que tem sido apresentado em livros didáticos. Química Nova na Escola, v. 32 , n. 2 , p. $107-119,2010$

CHAVES, L. M. M. P.; SANTOS, W. L. P. e CARNEIRO, M. H. S. História da ciência no estudo de modelos atômicos em livros didáticos de química. Química Nova na Escola, v. 36, n. 4, p. 269279, 2011.

COOK, M. P. Visual representations in science education: The influence of prior knowledge and cognitive load theory on instructional design principles. Science Education, v. 90, n. 6, p. 1073-1091, 2006.

DARROZ, L. M.; ROSA, C. T. W. e GIARETTA, P. H. Uso de imagens esportivas no ensino de mecânica: uma análise nos livros didáticos de física. Investigações em Ensino de Ciências, v. 22, n. 3, p. 125144, 2017.

ECO, U. Semiótica e filosofia da linguagem. São Paulo: Instituto Piaget. 2001. $328 \mathrm{p}$

GKITZIA, V.; SALTA, K. e TZOUGRAKI, C. Development and application of suitable criteria for the evaluation of chemical representations in school textbooks. Chemistry Education Research and Practice, v. 12, n. 1, p. 5-14, 2011.

GOES, L. F.; NOGUEIRA, K. S. C. e FERNANDEZ, C. A representação das reações redox através das imagens em livros didáticos brasileiros de química. Acta Scientiae, v. 20, n. 2, 2018.

GOES, L. F.; CHEN, X.; NOGUEIRA, K. S. C.; FERNANDEZ, C. e EILKS, I. An analysis of the visual representation of redox reactions and related content in Brazilian secondary school chemistry textbooks. Science Education International, v. 31, n. 3, p. 313-324, 2020.

HAN, J. Y. e ROTH, W. M. Chemical inscriptions in Korean textbooks: semiotics of macro-and microworld. Science Education, v. 90, n. 2, p. 173-201, 2006.

JOHNSTONE, A. H. Teaching of chemistry-logical or psychological? Chemistry Education Research and Practice, v. 1, n. 1, p. 9-15, 2000.

The development of chemistry teaching: A changing response to changing demand. Journal of Chemical Education, v. 70, n. 9, p. 701, 1993.

LATOUR, B. e WOOLGAR, S. A vida de laboratório: a produção dos fatos científicos. Rio de Janeiro: Relume Dumará, 1997. 310 p. 
LEMES, A. F. G.; SOUZA, K. A. F. D. e CARDoso, A. A. Representações para o processo de dissolução em livros didáticos de Química: o caso do PNLEM. Química Nova na Escola, p. 184190, 2010.

LIMA, M. S. e QUEIROZ, S. L. Modelo semiótico de leitura de inscrições: aplicação na educação em química. Química Nova, v. 43, n. 7, p. 987-997, 2020.

LIMA, M. S. e QUEIROZ, S. L. Letramento gráfico no ensino superior de química. Investigações em Ensino de Ciências, v. 26, n. 2, p. 170-195, 2021.

MATOS, A. C. S., TEIXEIRA, D. D., SANTANA, I. P., SANTIAGO, M. A., PENHA, A. B., MOREIRA, B. C. T. e CARVALHO, M. F. A. Nomenclatura de compostos orgânicos no ensino médio: influência das modificações na legislação a partir de 1970 sobre a apresentação do livro didático e as concepções de cidadãos. Química Nova na Escola, v. 31, n. 1, p. 40-45, 2009.

MCTIGUE, E. M. e SLOUGH, S. W. Student-accessible science texts: Elements of design. Reading Psychology, v. 31, n. 3, p. 213-227, 2010.

MELONI, R. A. e LOPES, A. C. Produção de sentidos pelas imagens em livros didáticos de química. Ciência \& Educação (Bauru), v. 26, e20052, 2020.

MIRANDA, C. L.; PEREIRA, C. S.; MATIELLO, J. R. e REZENDE, D. B. Modelos didáticos e cinética química: considerações sobre o que se observou nos livros didáticos de química indicados pelo PNLEM. Química Nova na Escola, v. 37, n. 3, p. 197-203, 2015.

MOREIRA, M. C. A. e BATISTA, F. R. S. A química em livros didáticos para o ensino médio: uma análise do discurso imagético. Revista de Educação, Ciências e Matemática, v. 8, n. 3, p. 151-166, 2018.

NYACHWAYA, J. M. e GILLASPIE, M. Features of representations in general chemistry textbooks: a peek through the lens of the cognitive load theory. Chemistry Education Research and Practice, v. 17, n. 1, p. 58-71, 2016.

PAZINATO, M. S.; BRAIBANTE, M. E. F.; MIRANDA, A. C. G. e FREITAS, R. T. G. Análise dos recursos visuais utilizados no capítulo de ligações químicas dos livros didáticos do PNLD 2015. Acta Scientiae, v. 18, n. 1, 2016.

POZZER, L. L. e ROTH, W. M. Prevalence, function, and structure of photographs in high school biology textbooks. Journal of Research in Science Teaching, v. 40, n. 10, p. 1089-1114, 2003.

ROTH, W. M. Reading graphs: contributions to an integrative concept of literacy. Journal of curriculum studies, v. 34, n. 1, p. 1-24, 2002.

ROTH, W. M.; POZZER-ARDENGHI, L. e HAN, J. Y. Critical graphicacy: Understanding visual representation practices in school science. Vol. 26. Dordrecht: Springer Science \& Business Media, 2005. $285 \mathrm{p}$.
ROTH, W. M; BOWEN, G. M. e MCGINN, M. K. Differences in graph-related practices between high school biology textbooks and scientific ecology journals. Journal of Research in Science Teaching, v. 36, n. 9, p. 977-1019, 1999.

ROZENTALSKI, E. e PORTO, P. A. Diagramas de energia de orbitais em livros didáticos de Química Geral: uma análise sob o viés da semiótica Peirceana. Ciência \& Educação (Bauru), v. 24, n. 2, p. 449-466, 2018.

. Imagens de orbitais em livros didáticos de química geral no século XX: uma análise semiótica. Investigações em Ensino de Ciências, v. 20, n. 1, p. 181-207, 2015.

SILlOS, A. E. e SANTOS, W. L. P. Percepções de alunos do ensino médio sobre o livro didático de Química. In: ENCONTRO NACIONAL DE PESQUISA EM EDUCAÇÃO EM CIÊNCIAS, 9., 2013, Águas de Lindóia. Caderno de Resumos. Águas de Lindóia: Associação Brasileira de Pesquisa em Educação em Ciências, 2013.

SILVA, G. S.; BRAIBANTE, M. E. F. e PAZINATO, M. S. Os recursos visuais utilizados na abordagem dos modelos atômicos: uma análise nos livros didáticos de Química. Revista Brasileira de Pesquisa em Educação em Ciências, v. 13, n. 2, p. 159-182, 2013.

SILVA, J. C.; MOTA, J. M. V. e WARTHA, E. J. Inscrições químicas em livros didáticos de química: uma análise semiótica das representações sobre fases da matéria. Revista de Ensino de Ciências e Matemática, v. 2, n. 1, p. 69-80, 2011.

SILVA, K. A. P. e ALMEIDA, L. M. W. A percepção da matemática em livros didáticos de química. Ensaio: Pesquisa em Educação em Ciências, v. 21, e10482, 2019.

SLOUGH, S. W.; MCTIGUE, E. M.; KIM, S. e JENNINGS, S. K. Science textbooks' use of graphical representation: a descriptive analysis of four sixth grade science texts. Reading Psychology, v. 31, n. 3, p. 301-325, 2010.

TOLEDO, E. J. L. e FERREIRA, L. H. Concepções estereotipadas sobre o aquecimento global em livros didáticos de química. Revista Brasileira de Ensino de Ciência e Tecnologia, v. 10, n. 2, p. 1-22, 2017.

UPAHI, J. E. e RAMNARAIN, U. Representations of chemical phenomena in secondary school chemistry textbooks. Chemistry Education Research and Practice, v. 20, n. 1, p. 146-159, 2019.

VASSÃO, C. F. Elementos do ensino superior: o livro didático, a biblioteca e a química geral teórica. Dissertação (Mestrado) Universidade Federal do Rio Grande do Sul, Porto Alegre, 2018.

VOJÍR, K. e RUSEK, M. Science education textbook research trends: a systematic literature review. International Journal of Science Education, v. 41, n. 11, 2019. 